\title{
Low-temperature crystallization of thin silicate layer on crystalline Fe dust
}

\author{
Chihiro Kaito, Akihito Kumamoto, Yoshio Saito, and Ryoichi Ono \\ Laboratory for Nano-Structure Science, Department of Physics, Ritsumeikan University, \\ 1-1-1 Nojihigashi, Kusatsu-shi, Shiga 525-8577, Japan
}

(Received July 31, 2008; Revised October 2, 2008; Accepted October 6, 2008; Online published February 12, 2010)

\begin{abstract}
The crystallization of an amorphous $\mathrm{SiO}$ layer covering Fe crystal grains has been clarified by high-resolution transmission electron microscopic (HRTEM) observation. Cristobalite crystals were produced preferentially on the (110) surface of Fe particles by the oxidation of silicon crystallites in the SiO layer, i.e. the oxidation energy of the silicon crystallites resulted in the epitaxial growth of the oxide layer on the Fe surface. The chemical reaction energy due to the oxidation of silicon crystallites in the $\mathrm{SiO}$ layer was concentrated at the interface of the crystal and the amorphous layer. Crystal growth took place from the Fe grain surface.
\end{abstract}

Key words: Low-temperature crystallization, silicate layer, crystalline dust, crystobalite, oxidation energy.

\section{Introduction}

To explain how cometary silicates crystallize under pressure in volatile interstellar ice in their parent comets, we experimentally demonstrated the possibility of a chemical reaction-driven crystallization (Kaito et al., 2007), which is called nonthermal crystallization (Yamamoto and Chigai, 2005; Yamamoto et al., 2010), using laboratory-synthesized amorphous Mg-bearing silicate grains (Kamitsuji et al., 2005). If the crystalline grain surface is covered with an amorphous silicate layer, the crystallization of the amorphous silicate layer may be different due to the different rates of thermal diffusion between amorphous and crystal layers, as observed during the crystallization of a carbon layer covering Pt clusters (Shintaku et al., 2006; Kaito et al., 2007). In a previous successful low-temperature crystallization of amorphous dust, iron grains covered with a $\mathrm{SiO}$ layer were used as the model sample, as schematically shown in Fig. 1.

In a previous study (Kaito and Shimizu, 1984), a vacuumdeposited $\mathrm{SiO}$ film was shown to be composed of $\mathrm{Si}$ and $\mathrm{SiO}_{2}(\alpha$-cristobalite) crystallites about $1 \mathrm{~nm}$ in diameter. By heating the film in air at various temperatures up to $500^{\circ} \mathrm{C}$, the film changed from orange to being transparent while maintaining an amorphous structure with a halo diffraction pattern. Intensity analyses of the electron diffraction (ED) pattern and infrared sopectroscopy were carried out to evaluate the structure alteration (Morioka et al., 1998). The mixed film of $\mathrm{Si}$ and $\mathrm{SiO}_{2}$ altered from $\alpha$-cristobalite to $\beta$ cristobalite $\left(250^{\circ} \mathrm{C}\right)$ and $\beta$-quartz $\left(500^{\circ} \mathrm{C}\right)$ accompanied by the oxidation of Si crystallites in air. Infrared spectroscopy was carried out to evaluate the structure alteration (Morioka et al., 1998). In this paper, Fe crystal grains covered with $\mathrm{SiO}$ film were heated at $100^{\circ} \mathrm{C}$ in the stable region for $\alpha$ -

Copyright (C) The Society of Geomagnetism and Earth, Planetary and Space Sciences (SGEPSS); The Seismological Society of Japan; The Volcanological Society of Japan; The Geodetic Society of Japan; The Japanese Society for Planetary Sciences; TERRAPUB.

doi:10.5047/eps.2008.10.002 cristobalites in air. The alteration of the $\mathrm{SiO}$ film was detected by HRTEM and is discussed as a low-temperature crystallization effect due to the oxidation energy of silicon crystallites in the $\mathrm{SiO}$ film.

\section{Experimental}

Fe wire $(0.5-\mathrm{mm} \phi)$ was wound on the tungsten wire with a $0.5 \mathrm{~mm} \phi$ filament, which had been preheated in a vacuum of $10^{-5}$ Torr. The chamber was a glass cylinder $(17 \mathrm{~cm}$ diameter and $30 \mathrm{~cm}$ height) covered with stainless steel on top and connected to a high-vacuum exhaust through a valve at its bottom. After evacuation of the chamber, the iron particles were produced by evaporation in Ar gas at 80 Torr. The particles were collected on a glass plate $10 \mathrm{~cm}$ above the evaporation source. Immediately after the preparation of iron grains, the chamber was evacuated to $10^{-6}$ Torr, and $\mathrm{SiO}$ powder was evaporated from a $\mathrm{W}$ boat without exposure to air. The Fe particles covered with a $\mathrm{SiO}$ layer were removed from the vaccum system. The specimen was placed on the standard transmission electron microscope (TEM) grid and observed using an H-9000NAR TEM. The observation points were determined by placing the specimen on an electron microscopic holder, and the specimen was then heated in a furnace at $100^{\circ} \mathrm{C}$ in air. The alteration of the specimen was observed and analyzed at the same specimen position throughout the study.

\section{Discussion}

Figure 2(a) and (b) shows TEM images of Fe crystalline grains covered with a thin amorphous $\mathrm{SiO}$ layer and the specimen after heat-treatment at $100^{\circ} \mathrm{C}$ for $24 \mathrm{~h}$ in air, respectively. The same positions of the specimen are presented. As shown in the enlarged image in Fig. 2(a), the surface of each iron particle was covered with an amorphous $\mathrm{SiO}$ layer. The $\mathrm{SiO}$ was evaporated onto one side of the iron particles. However, the thickness difference seen in the enlarged image suggests that the entire iron grain surface was covered with a thin SiO layer. This suggests that the 


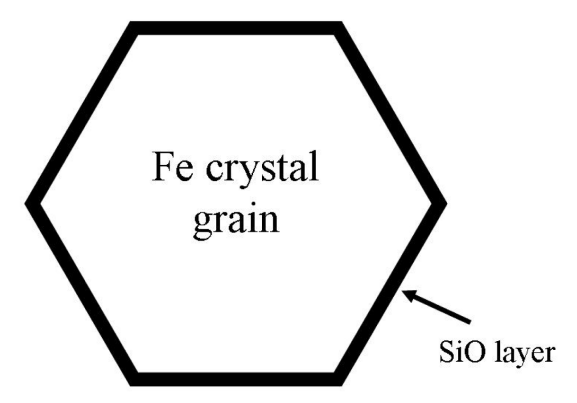

Fig. 1. Schematic model of Fe crystal grain covered with thin amorphous SiO layer.
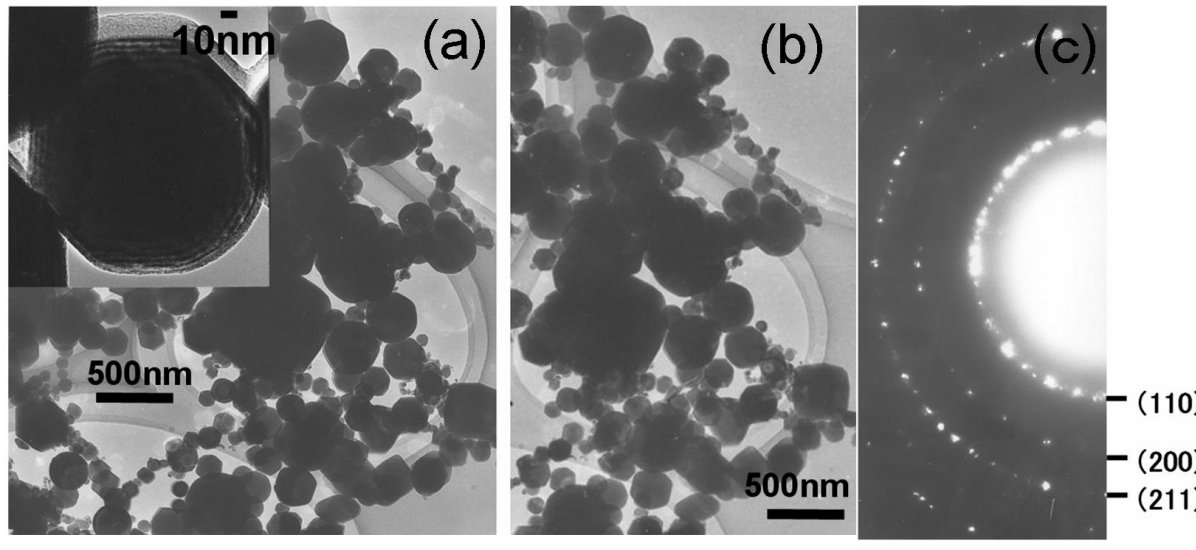

$\mathrm{Fe}$

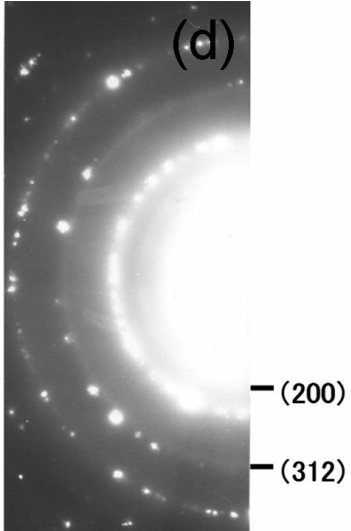

$\alpha$ - cristobalite

Fig. 2. Iron grain surface covered with SiO layer without exposure to air (a). The corresponding ED pattern (c) shows the iron crystal grain. The formation of a natural oxide layer was not observed. By heating the specimen at $100^{\circ} \mathrm{C}(\mathrm{b})$, the diffused cristobalite crystal rings appeared (d).

evaporated $\mathrm{SiO}$ covered the iron particle by the surface migration of $\mathrm{SiO}$ molecules. The ED patterns corresponding to the TEM images are shown in Fig. 2(c) and (d). The ED pattern in Fig. 2(c) shows both the existence of iron grains and the absence of oxide diffraction rings $\left(\mathrm{Fe}_{3} \mathrm{O}_{4}\right)$, which generally appeared when a fresh iron particle was exposed to air (Tamura et al., 2003). Therefore, it can be concluded that iron particle surfaces were covered with an amorphous layer of $\mathrm{SiO}$. After heating for $24 \mathrm{~h}$ in air at $100^{\circ} \mathrm{C}$, the $\mathrm{ED}$ pattern shows the existence of $\alpha$-cristobalite crystallites, as can be seen in the diffraction pattern in Fig. 2(d). This suggests that the amorphous $\mathrm{SiO}$ layer was altered to a $\beta-\mathrm{SiO}_{2}$ film.

Figure 3 shows an enlarged image of Fe grains after heating at $100^{\circ} \mathrm{C}$ for $24 \mathrm{~h}$. The most common form of grown iron particles is a rhombic dodecahedron covered with 12 (110) planes (Kaito and Fujita, 1986). Such particles can be seen as different shapes along the zone axis. An enlargement of part of the image in Fig. 3(a) is shown in Fig. 3(b) where the (110) lattice of an iron particle can be clearly seen. The parallel fringes on the $\mathrm{SiO}_{2}$ film region indicate the parallel growth of $\alpha-\mathrm{SiO}_{2}$ (202) and (101) planes, i.e., $(110)_{\mathrm{Fe}} / /(101)_{\mathrm{SiO}_{2}}$. This suggests that the $\mathrm{SiO}$ layer was altered to a crystalline $\mathrm{SiO}_{2}$ layer during heating at $100^{\circ} \mathrm{C}$ in air by the oxidation of Si crystallites on the surface of crystalline iron grains. The agreement between the lat-

\section{4 hour}

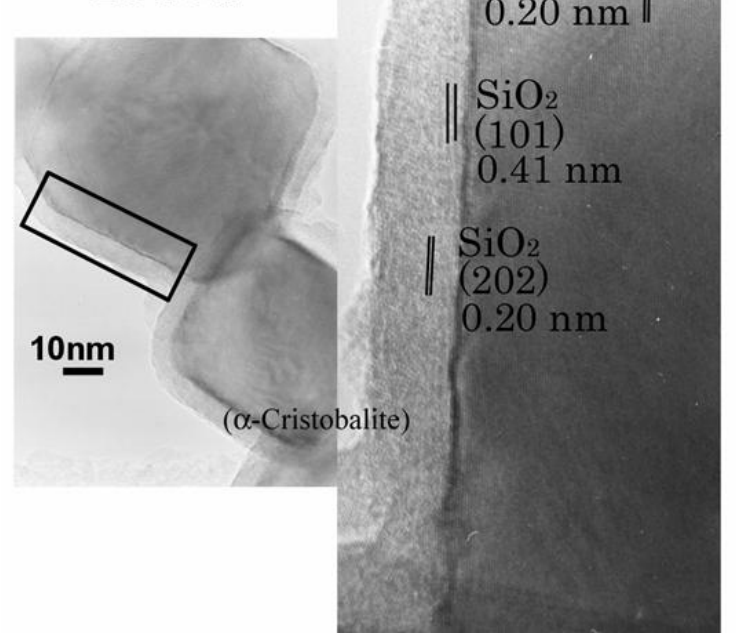

Fig. 3. After heating at $100^{\circ} \mathrm{C}$ for $24 \mathrm{~h}$, the HRTEM image shows that (202) $\left(a_{0}=0.2019 \mathrm{~nm}\right)$ and $(101)(0.405 \mathrm{~nm})$ crystals appeared parallel to the (110) surface of Fe. An arrow indicates the (110) lattice. 


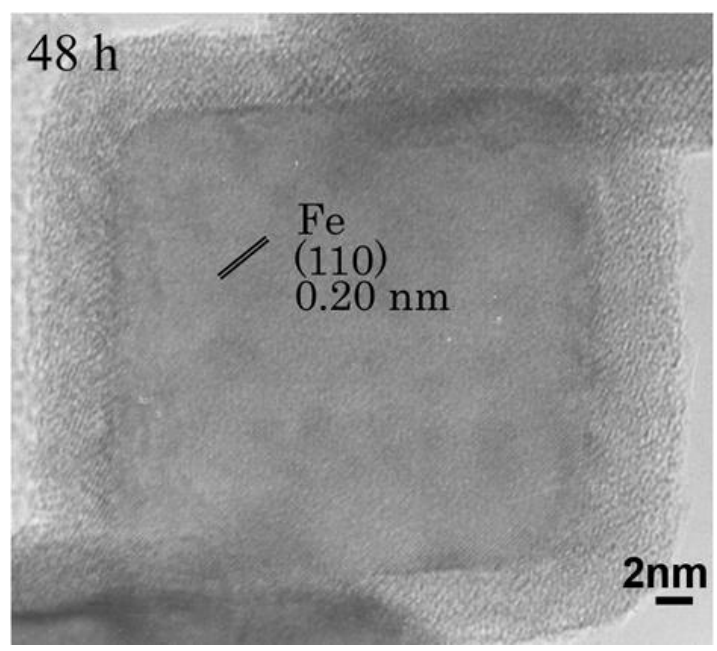

Fig. 4. The Fe particle was cubic because the (110) lattice can be seen at its corner. The growth of (101) and (202) cristobalite crystallites took place along the (110) plane of Fe.

tice of $\mathrm{Fe}(110)(d=0.202 \mathrm{~nm})$ and that of $\alpha-\mathrm{SiO}_{2}(202)$ $(d=0.2019 \mathrm{~nm})$ is very good, i.e., the growth of the (202) layer took place at the least energy at the interface. The (101) lattice fringes were observed at part of the interface between the iron particle and the silicate layer.

Figure 4 also shows the cubic shape of a Fe grain covered with a $\mathrm{SiO}$ layer after heating at $100^{\circ} \mathrm{C}$ for $48 \mathrm{~h}$. Since the (110) lattice of Fe can be seen along the edge of the cube, the iron particle shown in Fig. 4 was cubic and composed of six $\{100\}$ planes. The (101) and (202) planes of $\mathrm{SiO}_{2}$ remained parallel with the (110) plane of the Fe particle.

Since the mean free path of phonons in the crystal is of micrometer order, and the mean free path in the amorphous $\mathrm{SiO}$ layer is a few nanometers, i.e., the crystallite size, the oxidation energy of silicon crystallites in the SiO layer diffuses to the iron crystal grain. Therefore, the thermal energy due to the oxidation accumulates at the iron grain interface. This energy causes the crystallization of the $\mathrm{SiO}$ layer to $\mathrm{SiO}_{2}$ due to the oxidation energy of the $\mathrm{Si}$ crystallites and diffusion reaction with air. The parallel relation at the interface between $\mathrm{Fe}$ and $\mathrm{SiO}_{2}$ occurred due to a minimum in interface energy. This result supports the theory of lowtemperature crystallization by Yamamoto et al. (2010). The oxidation energy of Si crystallites drives the crystallization of the $\mathrm{SiO}_{2}$ layer.

Simple silicates evaporate to form $\mathrm{SiO}$, the $\mathrm{Mg}$ atom, the $\mathrm{Fe}$ atom, and $\mathrm{O}_{2}$ vapor and solid $\mathrm{SiO}, \mathrm{MgO}$, and $\mathrm{FeO}$ (Nuth et al., 1999). Iron exists largely as metallic species in the mixture film of $\mathrm{Fe}$ and $\mathrm{SiO}$ (Suzuki et al., 2000). If the iron grain is exposed in air, the grain surface is covered with magnetite phase and oxidation proceeds by the migration of iron atoms (Kaito et al., 1973). The reaction between $\mathrm{Fe}$ and $\mathrm{SiO}$ takes place above $1100 \mathrm{~K}$ (Hallenbeck et al.,
1998). The crystalline $\mathrm{SiO}_{2}$ growth on the iron grain surface in $\mathrm{O}_{2}$ atmosphere results in low-temperature crystallization during the comet-formation process or commentary silicate crystallization as well as the previous experimental demonstration on the possibility of chemical-reaction-driven crystallization for the $\mathrm{Mg}$-bearing silicate grain (Kaito et al., 2007). The migration of iron atoms to the SiO layer hardly occurred at low temperature.

Acknowledgments. The authors thank Joseph A. Nuth III of NASA/GSFC and the reviewers for valuable comments. This research was supported in part by the Ministry of Education, Science, Sports and Culture of Japan, Grant-in Aid for Scientific Research on Priority Areas, Development of Extra-Solar Planetary Science. This work was also supported in part by Ritsumeikan University Grant-in-Aid of Internationalization.

\section{References}

Hallenbeck, S. L., J. A. Nuth, and P. L. Daukantas, Mid-infrared spectral evolution of amorphous magnesium silicate smoke annealed in vacuum: Comparison to cometary spectra, Icarus, 131, 198-209, 1998.

Kaito, C. and T. Shimizu, High resolution electron microscopic studies of amorphous SiO film, Jpn. J. Appl. Phys., 23, L7-L8, 1984.

Kaito, C. and K. Fujita, Morphology and growth of ultra fine particles, Sci. Form, 2, 37-48, 1986.

Kaito, C., K. Fujita, and H. Hashimoto, Electron-microscopic study of oxidation processes by metal fine particles, Jpn.J. Appl. Phys., 12, 486496, 1973.

Kaito, C., Y. Miyazaki, A. Kumamoto, and Y. Kimura, Exothermic chemical reactions can drive nonthermal crystallization of amorphous silicate grains, Astrophys. J., 666, L57-L60, 2007.

Kaito, C., R. Ono, R. Sasaki, M. Kurumada, M. Saito, Y. Kimura, and S. Oyagi, Structural alteration of nanostructure carbon particles caring Pt clusters in $\mathrm{H}_{2}$ and $\mathrm{O}_{2}$ gases, Jpn. J. Appl. Phys., 46, L1141-L1142, 2007.

Kamitsuji, K., H. Suzuki, Y. Kimura, T. Sato, and C. Kaito, Crystalline $\mathrm{Mg}_{2} \mathrm{SiO}_{4}$ and amorphous Mg-bearing silicate grain formation by coalescence and growth, Astron. Astrophys., 429, 205-208, 2005.

Morioka, T., S. Kimura, N. Tsuda, C. Kaito, Y. Saito, and C. Koike, Study of the structure of silica film by infrared spectroscopy and electron diffraction analyses, Mon. Not. R. Astron. Soc., 299, 78-82, 1998.

Nuth III, J. A., S. L. Hallenbeck, and F. J. M. Rietmeijer, Interstellar and Interplanetary grains recent developments and new opportunities for experimental chemistry, Earth Moon Planets, 80, 73-112, 1998.

Shintaku, M., H. Suzuki, and C. Kaito, High resolution transmission electron microscopy of structural change in carbon particle carrying Pt clusters, Jpn. J. Appl. Phys., 45, 9272-9275, 2006.

Suzuki, N., S. Kimura, T. Nakada, C. Kaito, Y. Saito, and C. Koike, Correlation between crystallographic structure and Infrared spectra of silicon oxide films containing iron or magnesium atoms, Meteor. Planet. Sci., 35, 1269-1273, 2000.

Tamura, K., Y. Kimura, H. Suzuki, O. Kido, T. Sato, T. Tanigaki, M. Kurumada, Y. Saito, and C. Kaito, Structure and Thickness of Natural Oxide on Layer on Ultrafine Particle, J. Appl. Phys., 42, 7489-7492, 2003.

Yamamoto, T. and T. Chigai, A mechanism of crystallization of cometary silicates, Highlights Astron., 13, 522-524, 2005.

Yamamoto, T., T. Chigai, H. Kimura, and K. K. Tanaka, Nonthermal crystallization of amorphous silicates in comets, Earth Planets Space, 62, this issue, 23-27, 2010.

C. Kaito (e-mail: kaito@se.ritsumei.ac.jp), A. Kumamoto, Y. Saito, and R. Ono 